\title{
Green Spaces in Residential Areas of Dar es Salaam City: Types, Coverage and Uses
}

\author{
Nicholaus Mwageni ${ }^{1} \&$ Robert Kiunsi ${ }^{2}$ \\ ${ }^{1}$ School of Environmental Science and Technology, Ardhi University, Dar es Salaam, Tanzania \\ ${ }^{2}$ Retired Associate Professor, School of Environmental Science and Technology Ardhi University, Dar es Salaam, \\ Tanzania \\ Correspondence: Nicholaus Fabian Mwageni, School of Environmental Science and Technology, Ardhi University, \\ Dar es Salaam, Tanzania. Tel: 255-7-1279-0905. E-mail: nicholausmwageni2012@gmail.com
}

Received: March 9, 2021

Accepted: April 28, 2021

Online Published: April 28, 2021

doi:10.5539/jsd.v14n3p121

URL: https://doi.org/10.5539/jsd.v14n3p121

\begin{abstract}
Green spaces in urban areas including in Dar es Salaam City provide multiple ecological, social and economic benefits. Despite their benefits they are inadequately documented in terms types, coverage and uses. This paper attempts to provide information on types, coverage and uses of green space in Dar es Salaam City. A number of methods including literature review, interpretation of remotely sensed image, interviews, focus group discussions and questionnaires were used to document city greenery. The research findings show that residential greenery is made up of greenery found within and external to plots. The dominant green spaces external to residential plots were natural and semi natural vegetation while within plots were woody plants, plots farms vegetable and ornamental gardens. Distribution of greenery varied among the wards due to differences in building density and distance from the city centre. Natural and semi natural vegetation increased with decrease of building density and increase of distance from the city centre, while the number of plots with trees for shade increased with increase of building density. Only Kawe ward that had greenery above Tanzania space planning standards, the other three wards which are informal settlements had green space deficit. Three quarters of the households use green spaces for shade provision and cooling, two thirds as a source of food products and a quarter for recreation and aesthetic purposes. The study reveals that Dar es Salaam City residents invest predominantly on shade trees in their residential plots compared to other green space types.
\end{abstract}

Keywords: vegetation, open spaces, urban farms, shade, food provision and recreational

\section{Introduction}

Green spaces in urban context include all types of vegetated areas, water surfaces and unsealed and permeable surfaces (Bolund \& Hunhammar, 1999; Campbell, 2001; La Greca, La Rosa, Martinico, \& Privitera, 2011; Mensah, 2014; Mng'ong'o, 2005). Depending on the principal or key considerations used, urban green spaces can be categorized in number of ways. For instance based on ownership, Roy et al., (2018) categorized green spaces into three types of privately owned and used, open to use by general public and open to use upon payment. On the other hand, based on the nature, Mensah (2014) and Hassan (2015) provided five categorizes of green spaces of semiprivate space, designated greenery, public green areas, public and private tree plantations, rangeland and forests close to urban areas, natural forest under urban influence and trees planted for environmental protection and beautification.

Urban green spaces provide a wide range of ecosystem services that are broadly classified as provisioning, regulating, cultural and habitat services. Examples of provisioning services include provision of different types of food crops, fruits and medicinal plants (Costanza, d'Arge, et al., 1997b). Urban greenery keeps cities cool through the reduction of transmission of heat energy from the land surface to buildings and transpiration process (Tan $e t$ al. 2016); Wang et. al., 2014). According to Georgi \& Dimitriou (2010); Thani et al., (2018), urban greenery that provides shade can increase thermal comfort through reduction of solar radiations, air temperature, temperature of exterior surfaces, wind speed as well as increasing air humidity. Green spaces also act as natural carbon sinks through the sequestration of carbon and hence can contribute to climate change mitigation (Clothier et al., 2013). In terms of cultural and habitat services green spaces are used for relaxation, quietness, physical exercise, nature appreciation, aesthetics pleasure, privacy, social contact and solitude (Bolund et al., 1999; Jim \& Chen, 2006). 
This implies that, quality of urban environment and human being is positively influenced by abundance of green spaces diversity (Kopecká, Szatmári, \& Rosina, 2017).

However, expansion and intensification of urban activities compromise uses of green spaces in various ways including; i) reducing the size of un-built up areas ii) increasing urban greenery fragmentation and iii) destruction of physical links among open space patches (Esbah, Cook, \& Ewan, 2009). According to CLUVA (2013) many cities in the world have a deficit of green spaces. The deficit can lead to the reduction of ecosystem services which in turn can increase the possibility of increased occurrences of disaster events and reduction in environmental comfortability in urban areas (Delshammar et al., 2015). Thus, urban dwellers in order to continue enjoying services previously provided by green spaces employ technical solutions e.g. cooling services, which are much more expensive. In developing countries studies have revealed that green spaces are being depleted at an alarming rate. Such spaces are now occupying only small proportion of urban areas. Specific factors leading to green space degradation include rapid urbanization especially urban sprawl, limited enforcement of planning regulations and building codes, scarcity of data and over exploitation (Mensah, 2014). In addition, limited financial resources in many of the cities in developing countries makes it difficult to justify budget for green space provision, maintenance, and management (McPherson et al., 2005; CLUVA, 2013).

A number of studies concerning Dar es Salaam City on green space types, uses and coverage have been conducted including a research work done through a programme titled Climate Change and Urban Vulnerability Assessment in Africa (CLUVA) in 2013. According to CLUVA (2013), 61\% of Dar es Salaam land was covered by different types of green cover including trees, shrubs, grasses, cultivated crops, and water. It is important to note that greenery in the City is not uniformly distributed neither its coverage and uses. The existing empirical studies on green spaces firstly, do not show the distribution of types, coverage and uses of greenery specifically to residential areas. Secondly, do not differentiate greenery found within residential plots and those outside the plots. Thirdly, do not show changes in types, coverage and uses of green spaces with increasing distance from the City centre and planning status of a residential area. This study using data from four sampled wards attempts to highlight the current status of green space in residential areas in terms of spatial coverage, types and uses at ward level and also within and outside residential plots. The paper also attempts to show changes in green space types, coverage and uses with increasing distance from the City and the ward planning status. Hopefully this type of information can effectively be used to plan and manage the greenery in the City.

\section{Methodology}

A number of methods and procedures were used in conducting this research including literature review on green spaces in urban areas, their uses and coverage. Interpretation, using a GIS system of remotely sensed image was done in order to map different types, coverage and uses of green spaces. Field work was carried out in which observations, measurements, interviews and questionnaires were conducted to verify the types, coverage and uses of green spaces in sampled wards and households.

\subsection{Sampling of Wards and Households}

The study was conducted in Dar es Salaam, a commercial city of Tanzania located in East Africa along the Indian Ocean. The City has a hot and humid climate with an average temperature of $29^{\circ} \mathrm{C}$ and experiences bimodal rainfall pattern with short rains starting from October to December and long rains from March to May. The City has the highest physical and population growth rate among the cities in Tanzania (Kiunsi, 2016; Lupala and Kiunsi, 2011). According to world population review, Dar es Salaam City is the third fastest growing city in Africa and ninth fastest growing city in the World (http://worldpopulationreview.com/world-cities/dar-es-salaamn population/;retrieved on $18^{\text {th }}$ June 2019). It is estimated that between 60 to 80 percent of the City's population live in informal settlements which are characterized by poor provision of social services (Kiunsi, 2016). Dar es Salaam City has five (5) Districts (Ilala, Temeke, Kinondoni, Kigamboni and Ubungo) which comprises of ninety (90) wards. Due to its rapid growth, the City has a higher conversion rate of green spaces for residential, commercial and industrial purposes than any other City in Tanzania (Kibassa and Shemdoe, 2016).

\subsubsection{Sampling of Wards}

The study was conducted in four sampled wards which were identified through a four step approach. The first step was identifying wards that were predominantly residential by using remote sensing image and GIS techniques. A total of 82 wards were identified as predominantly residential. The second step was to establish residential wards that had green spaces in which 60 wards were identified. The third step using ward building and the population density was to establish green space abundance in Wards. Using the remotely sensed image building density was obtained by counting the number of buildings in each ward and dividing it by area, while the population density was obtained by projecting the 2012 National census data. The assumption was that areas with high building and 
population density have low green space coverage and vice versa. The fourth and final step was the classification of wards with green spaces based on population and building density which resulted in four (4) classes as follows:

i Class one-very high population density(36,001-48,000people/sq.km) and building density $(3,601-4,800$ buildings/sq.km);

ii Class two-high population density(24,001-36,000people/sq.km) and building density (2,401-3,600 buildings/sq.km);

iii Class three- moderate population density(12,001-24,000 people/sq.km) and building density (1,201-2,400 buildings/sq.km) and

iv Class four-low population density ( $<12,000$ people/sq.km) and building density $(<1,200$ buildings/sq.km).

Wards within one particular class which were found to have similar characteristics of building and population density were differentiated by using green space index. The green space indices were obtained by dividing the total area (coverage) of green space by total area of the ward. Within each class, a Ward was picked as a sample representing other Wards. In class one, Makumbusho was chosen as the case study area out of four Wards; in class two, Mburahati was selected out of four Wards and in class three, Yombo Vituka was picked out of 15 Wards, while in class four, out of 37 Wards, Kawe was chosen. Figure 1 shows spatial location of case study areas and their proximity to the City centre. 


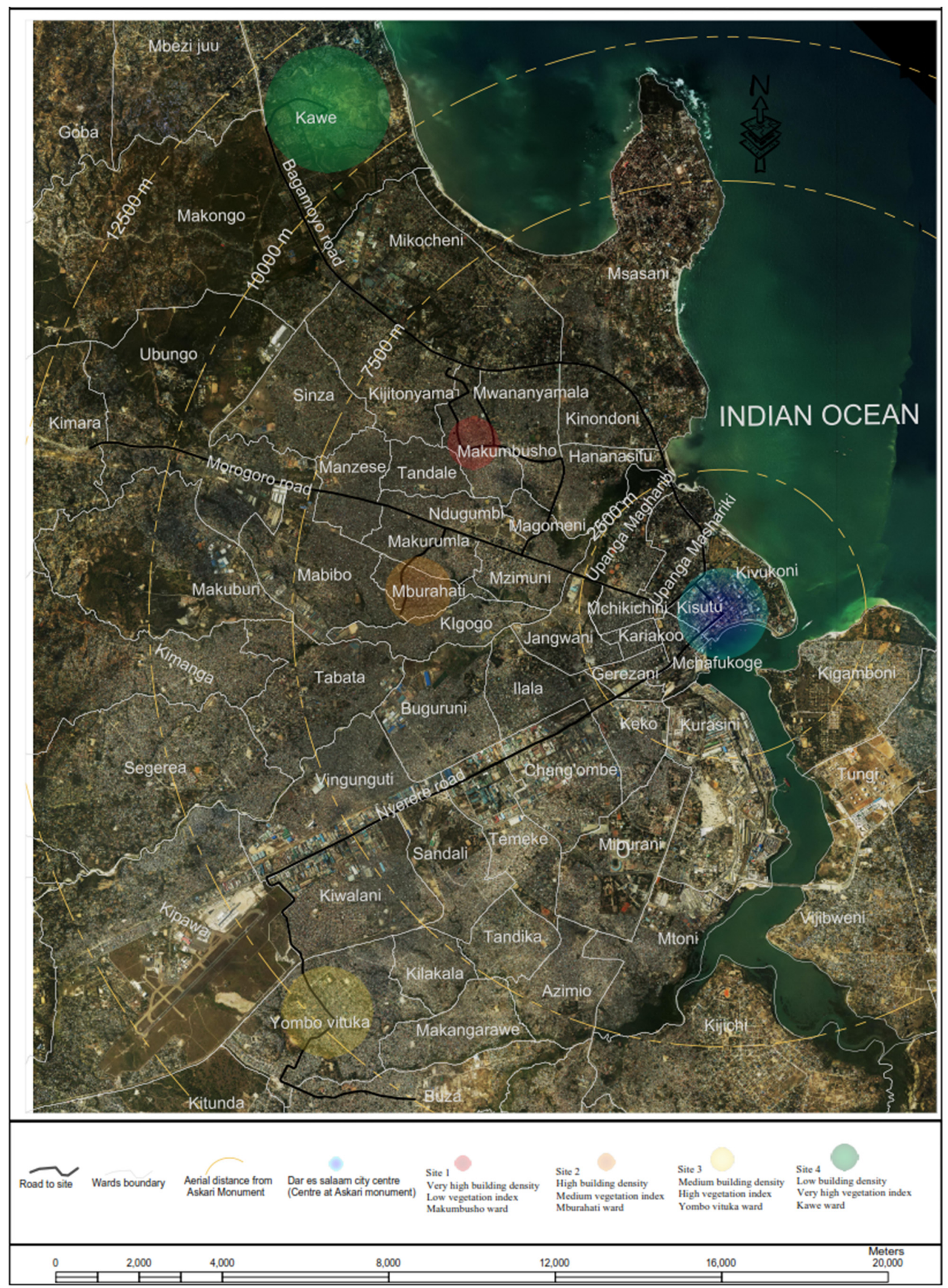

Figure 1. Spatial location of case study areas and their proximity to the City centre 


\subsubsection{Sampling of Households}

Household purposive sampling was conducted in order to establish types and uses of green spaces found in low and high land areas in the wards. This is due to the fact that the distribution and abundance of green spaces and their uses depend on among other things topographical nature of the area. The low land areas, which sometimes can be a wetland, might have a high abundance of green spaces than high land areas due to differences in soil fertility and soil moisture if all factors are kept constant (Karaca et al., 2018). Using a Digital Elevation Model (DEM), the wards were sub-divided into zones of high land areas (slope greater than 6\%) and low land areas (Slope lower than 6\%). A total of 511 households were sampled from the case study area.

\subsection{Methods}

The study employed a number of methods in collecting and analyzing data/information. These included; interpretation of remotely sensed image, field work verification, interviews, focus group discussions and questionnaires.

\subsubsection{Interpretation of Remote Sensing Image}

Ortho-rectified aerial imagery of 2017 with pixel resolution of $0.1 \mathrm{~m}$ image, sourced from the Ministry of Lands, Housing and Human Settlements Development (Tanzania) was used to establish the green space coverage, building density and planning status of settlements of case study areas. In interpreting the image, ArcGIS 10.3.1 software was applied using three main stages that included; initial office work, fieldwork and final office work. The types of green cover during image interpretation were identified based on colour, texture and pattern. During fieldwork, the type of green spaces, were verified through observations, focus group discussions, and transect walks. The green space classification used by this study was adopted and modified from Mensah (2014). Green space types within residential plot level were classified as woody plants (trees and shrubs), plot farms, allotments and ornamental gardens. The main types of greenery outside residential plots were natural and semi-natural vegetation; green ways; stream/rivers; play grounds; open spaces; ruderal (abandoned green space); urban farms, wetlands (with floating water plants); cemeteries/graveyards and seashore areas.

Building density was determined by making each building in a ward a point shapefile. Thereafter, the number of buildings in the ward was automatically generated by overlaying the point shapefile with wards boundary. The obtained building counts for each ward were divided by its area to get building density. Planning status of buildings was determined using spatial pattern of buildings and roads in the image. Areas that had orderly pattern buildings and roads were considered as planned and areas that had disorganized pattern were considered as not planned or informal

\subsubsection{Interviews and Focus Group Discussions}

Interviews and discussions with key informants were done involving local authority officials and selected community leaders. The focus groups were made up of six representing high and low land zones. In addition gender balance was observed in the formation of focus groups. Focus group discussions facilitated collection of information on settlement history as well as spatial distribution of green spaces, their uses and ranking in terms of their importance. During focus group discussions main points were noted down on large sheets of papers in a tabular format mounted on a wall. Data recorded on the wall-mounted papers were: type of green spaces found in the locality. For each type of greenery, the five (5) elements were elaborated; what use it has, who gets the benefit, changes of uses, what causes the changes and management initiatives in place.

\subsubsection{Household Questionnaire}

A total number of 511 households from all four case studies were involved during the questionnaire exercise. The essence of conducting household questionnaire within the settlements was firstly; to triangulate the information collected during interviews and focus group discussions and secondly, to get a deeper understanding of green space types, coverage, uses, and changes in uses. The household questionnaire was finalized after conducting focus group discussions. The questionnaire also intended to capture demographic data and land tenure type. During questionnaire exercise, data on the coverage of green spaces within a plot and their uses were collected through onsite measurements. In order to identify the households to be sampled in both high and low land areas, the zoned DEMs were overlaid with green spaces map. The overlaid map of green space and DEM was then subdivided into blocks of $0.02 \mathrm{~km}^{2}$ and within which the most greenery blocks that had a house(s) were marked as the potential households to be sampled. The choice of households in both high and low lands considered their proximity to open spaces and streams. Based on this approach the following are the households sampled in each ward: Makumbusho ward were 127, Kawe were 150, Mburahati were 100 and Yombo Vituka were 134. The socio economic profile of respondents from the four wards is shown in Table 1. Figure 2 shows Mburahati ward and its Sub-wards divided 
into high and low land areas and also indicating streams, open spaces and sampled households.

Table 1. Respondents characteristics in sample households (Mwageni, 2019)

\begin{tabular}{llcccc}
\hline \multirow{2}{*}{ Key characteristic } & \multicolumn{4}{c}{ Sample Settlement } \\
\multicolumn{1}{l}{ Gender } & Male & 69 & Makumbusho & Mburahati & Yombo Vituka \\
& Female & 81 & 56 & 47 & 42 \\
Income per & Minimum & 10,000 & 10,000 & 53 & 92 \\
month & Average & $657,533.3$ & 270,000 & 50,000 & 10,000 \\
(TZS) & Maximum & $10,000,000$ & $1,500,000$ & $1,500,000$ & $1,000,000$ \\
Age & Youth (18-35) & 49 & 32 & 14 & 33 \\
& Middle aged (35-45) & 26 & 27 & 26 & 30 \\
& Old (above 45 & 74 & 68 & 60 & 71 \\
Education & No school & 6 & 4 & 1 & 11 \\
level & Religious education & 0 & 0 & 1 & 1 \\
& Primary & 53 & 69 & 64 & 73 \\
& Secondary & 41 & 43 & 22 & 37 \\
& College/university & 48 & 11 & 12 & 12 \\
Religion & Buddhist & 0 & 1 & 0 & 1 \\
& Christian & 101 & 41 & 58 & 56 \\
& Muslim & 47 & 85 & 40 & 76 \\
Tenure & Home owner & 48 & 52 & 36 & 58 \\
information & Owned by relatives & 14 & 5 & 10 & 6 \\
& Residence care taker & 10 & 27 & 3 & 25 \\
& Tenants & 20 & & 12 & \\
\hline
\end{tabular}

1USD $\$=$ TZS 2330 


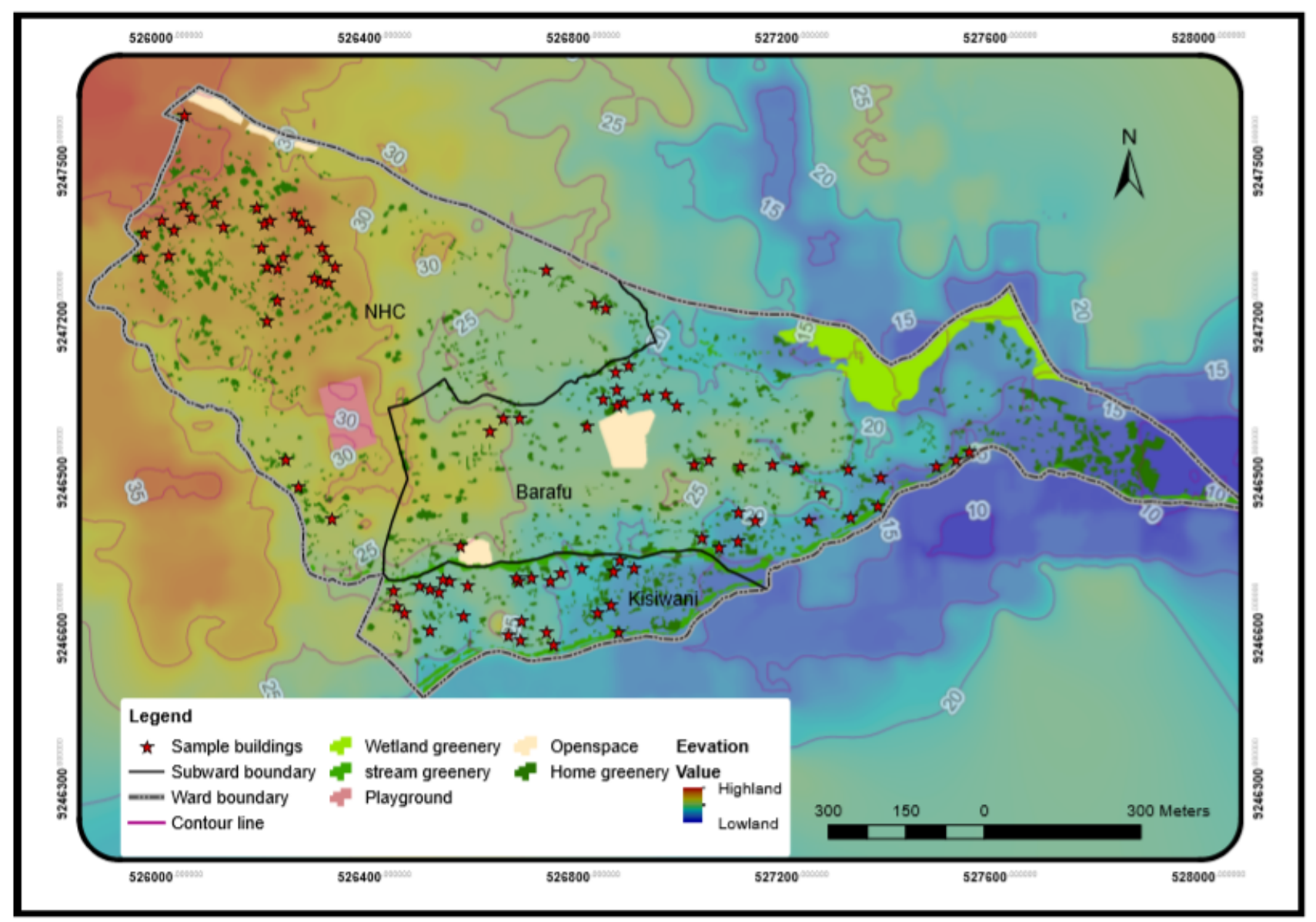

Figure 2. Distribution of sampled households according to topography and proximity to open spaces and stream in Yombo Vituka Ward

\section{Results}

The results on types, coverage and uses of green spaces are given at ward and plot levels. At the ward level green spaces are owned and used by different stakeholders including local government authorities, government institutions and local communities. Green spaces at the plot level are owned and used by respective households.

\subsection{Green Space at Ward Level}

In total, eleven green space types were identified in the case study areas even though there was a variation in terms of abundance between the wards. Greenery at the ward level is made up of green spaces found within and external to residential plots at spatial coverage of $34 \%$ and $66 \%$, respectively (Mwageni, 2019). Green spaces located within residential plots are owned and used by households. The main types of greenery external to residential plots includes natural and semi-natural vegetation characterized by cluster of trees greater than $5 \mathrm{~m}$ high, shrubs and grasses; green ways; stream/rivers; play grounds; open spaces; ruderal (abandoned green space); urban farms, wetlands (with floating water plants); cemeteries/graveyards and seashore areas. These are mostly owned by public and institutions including local government authorities.

Figure 3 shows the overall coverage of green space in the case study wards in which natural and semi-natural vegetation have the highest coverage followed by greenery in residential plots. Green space types with low spatial coverage are greenways, wetlands, playgrounds and cemeteries. Note that if the green spaces are classified into two main types of vegetation and none vegetation (seashore, wetlands, streams, and cemeteries), then $90 \%$ of greenery is either natural or semi-natural vegetation. 


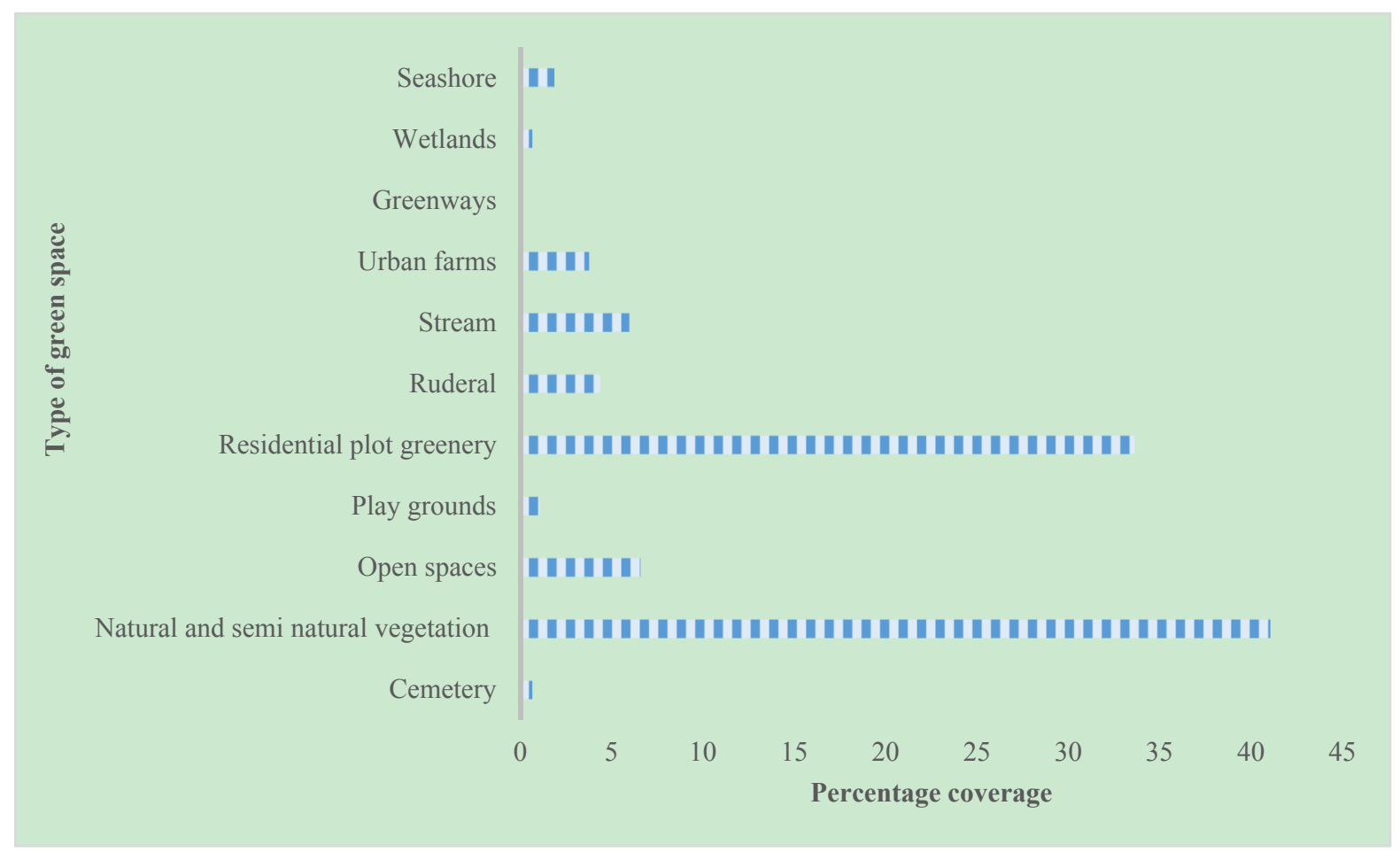

Figure 3. Types of green spaces at ward level

Table 2 shows the distribution of green spaces in the study wards. Overall, greenery space covers about $27 \%$ of the total area of the four wards. As seen from the data, Kawe Ward has the highest percentage $(43 \%)$ of land covered by green spaces, followed by Mburahati, Yombo Vituka and lastly, Makumbusho ward. The Table also shows that greenery in the wards increased with an increase in distance from the City centre. As per, Tanzania Green-space coverage standard (GN 93 (2018)), which uses population size and not the spatial extent of the area in determining coverage of green space in residential areas of all the case study settlements except for Kawe Ward, showed a deficit of green space coverage. Table 2 shows that deficit of greenery in the informal settlements decreased with increase in distance from City centre. 
Table 2. Total green space coverage within each case study ward

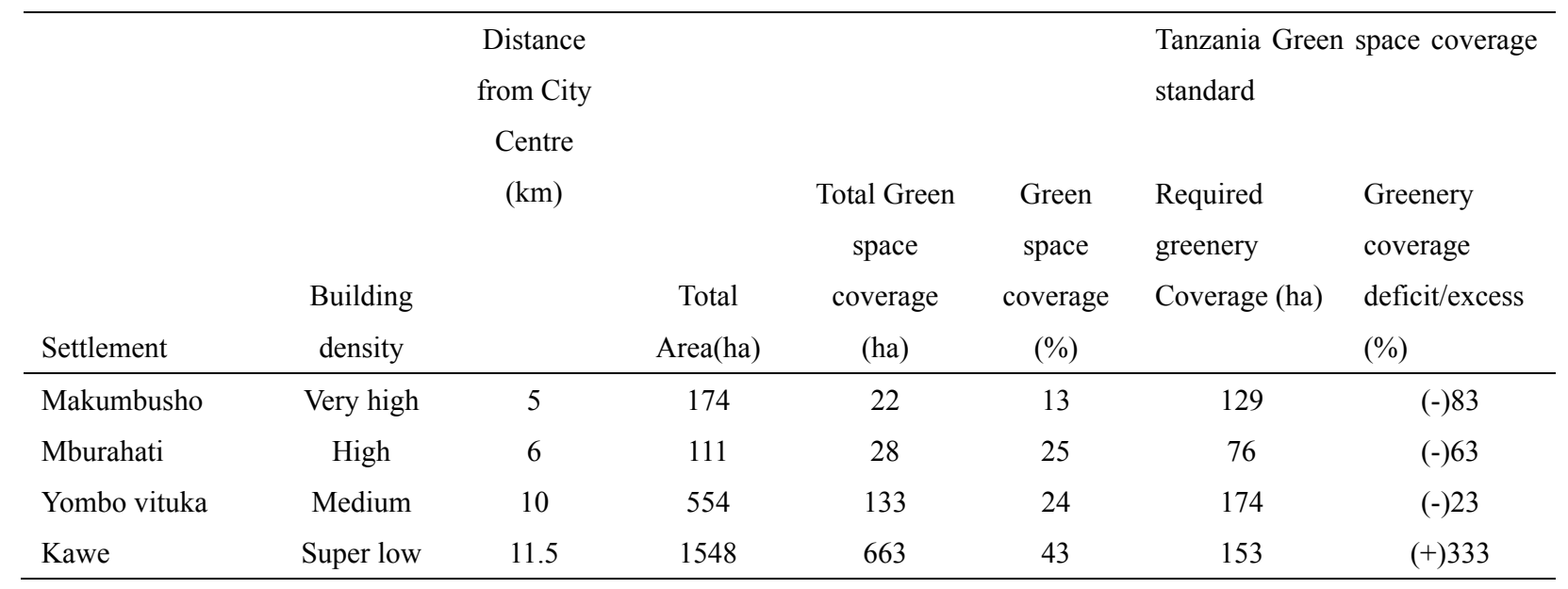

Figure 4 shows the distribution of greenery types and coverage in each ward and is generalized into three main categories. The first category is cemeteries and urban farms found in all the Wards but at low spatial coverage from less than one hectare to a maximum of 20 hectares. The Spatial-coverage of urban farms ranged from 1 ha in Mburahati to 19 ha in Yombo Vituka. For the cemetery, they ranged from 0.4 ha in Makumbusho ward to 3 ha in Yombo Vituka. The second category is natural and semi-natural vegetation, plot greenery, open spaces, streams and ruderal that are common in all wards but skewed in their spatial coverage. As an example, natural or seminatural vegetation coverage ranged from 3 ha in Makumbusho ward to 310 ha in Kawe ward, and open space ranged from 2 ha in Makumbusho to 49 ha in Kawe. The final category is the playgrounds, greenways, wetlands and seashore that did not appear in all wards. Playgrounds coverage ranged from zero in Yombo Vituka to 3 ha in both Mburahati and Makumbusho and 77 ha in Kawe; Greenways appeared only in Kawe and Yombo Vituka, wetlands in Mburahati and Makumbusho and seashore in Kawe ward only.

As shown above overall, none plot greenery dominates green space found in residential areas. The same results were obtained at the individual ward level, however, the ratio of none and plot greenery differed among the four wards. Kawe and Mburahati had the highest percentage of none plot greenery at $69 \%$ and $68 \%$, respectively, followed by Yombo Vituka at $57 \%$ and finally Makumbusho at $12 \%$.

Analysis of green spaces in sampled wards revealed that Kawe was the ward with the highest green space index of 0.51 , followed by Yombo Vituka with a green space index of 0.27 . Mburahati and Makumbusho were the wards with the lowest green space area with green space indices of 0.25 and 0.13 respectively. Analysis of Variance (ANOVA) evidenced that there is a statistical difference in green space indices among sampled wards with $p<.05$ for the four wards $(F(3,507)=1.44388 \times 1034), p=2 \times 10-16)$. Also, according to Tukey multiple comparisons of means there was a statistical difference between all sampled wards. The presence of sea shoreline, organizational greenery, large open spaces, and particularly Tanganyika Packers, might have contributed to the highest green space index at Kawe ward. Low indices in Mburahati and Makumbusho is because they are old settlements and are highly built up with high population density and are close to the City centre. 


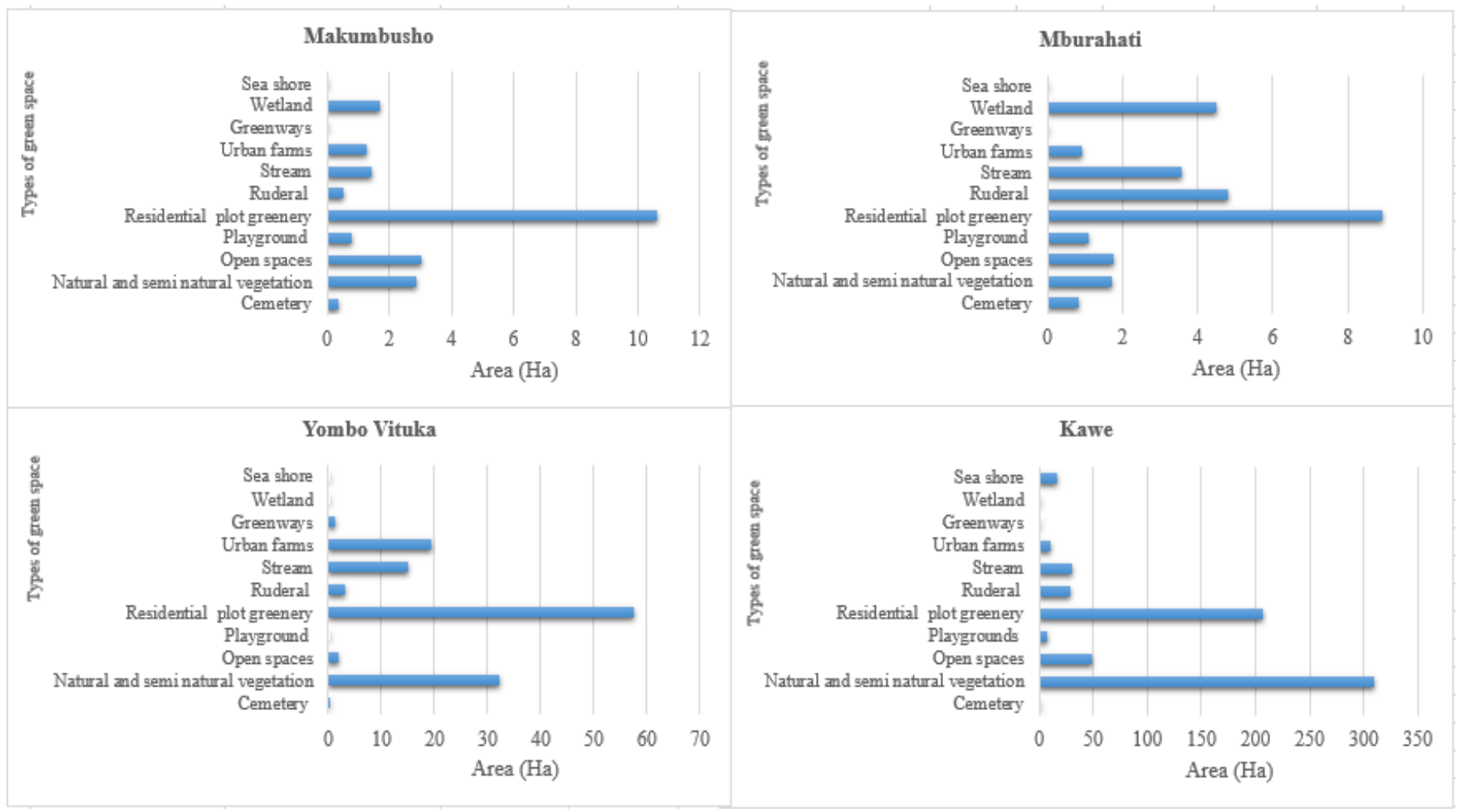

Figure 4. Green space coverage in case study settlements

\subsection{Green Spaces in Residential Plots}

Types of green spaces found in residential plots can broadly be classified into woody plants in terms of trees and shrubs, plot farms, allotments and ornamental gardens. Common types of woody plants in plots were neem, moringa, and ashok trees. Plot farms comprised of maize, coconut trees, mangoes, oranges, pawpaws, bananas, pigeon pea, cowpea plant and cassava. Common plant crops in vegetable gardens were spinach, lemon grass, genovese, tomato, okra and pumpkins. The ornamental gardens included palms, different types of shrubs, aloe vera, grasses and many other types of flowers. Green spaces at plot level were found in all wards but at different levels of occurrence in each ward. Presence of green spaces in plots of the four wards was as follows: woody plants and vegetable gardens were recorded in plots at $27 \%$, ornamental gardens at $26 \%$ and plot farms at $23 \%$.

Plot farms were found in all settlements except Kawe, probably due to its planning status and were distributed as follows: 38\% in Yombo Vituka, 35\% in Mburahati and 27\% in Makumbusho. The highest number of vegetable gardens was found in Kawe plots (47\%), followed by Yombo Vituka (33\%), Mburahati (11\%) and Makumbusho $(9 \%)$. The highest number of plots with ornamental gardens was in Kawe Ward (44\%), followed by Yombo Vituka (28\%), Mburahati (17\%) and Makumbusho (11\%).

Two thirds of the households had more than one type of green spaces even though some had only one and a few none at all. The following were the main combinations for plots that had more than one type of greenery. These included combined woody plants and ornamental gardens found mostly in planned plots of Kawe ward, followed by Yombo Vituka, an informal settlement; combination of plot farms, allotment and ornamental gardens found mostly in unplanned areas of Yombo Vituka followed by Makumbusho and Mburahati. The most dominant combination of green space types was woody plants and ornamental gardens $(12 \%)$ followed by plot farms, allotment and ornamental gardens (6\%). Other combinations of greenery in plots each were below $6 \%$. Plate 1 shows a typical combination of woody plants, allotments, ornamental and vegetable gardens and plot farms found in Makumbusho, Kawe, Mburahati and Yombo Vituka wards. Twelve percent of plots had single greenery of woody plants, allotments, plot farms, or ornamental gardens. Each of these greeneries was found in less than 5\% of the plots. The rest of the plots did not have greeneries at all due to a number of reasons including limited space for greenery activities, high maintenance costs and safety issues. In the context of safety, it was reported that people with bad intention sometimes use green spaces to hide. Besides, some tenants were reluctant to develop green spaces in rented houses since it is a long term investment. 


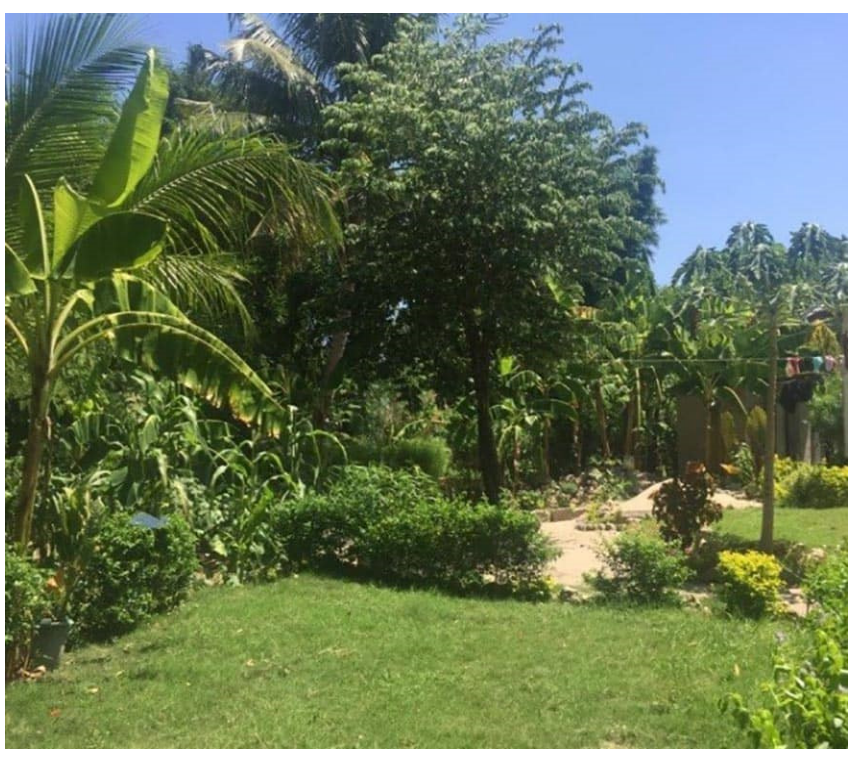

(a)

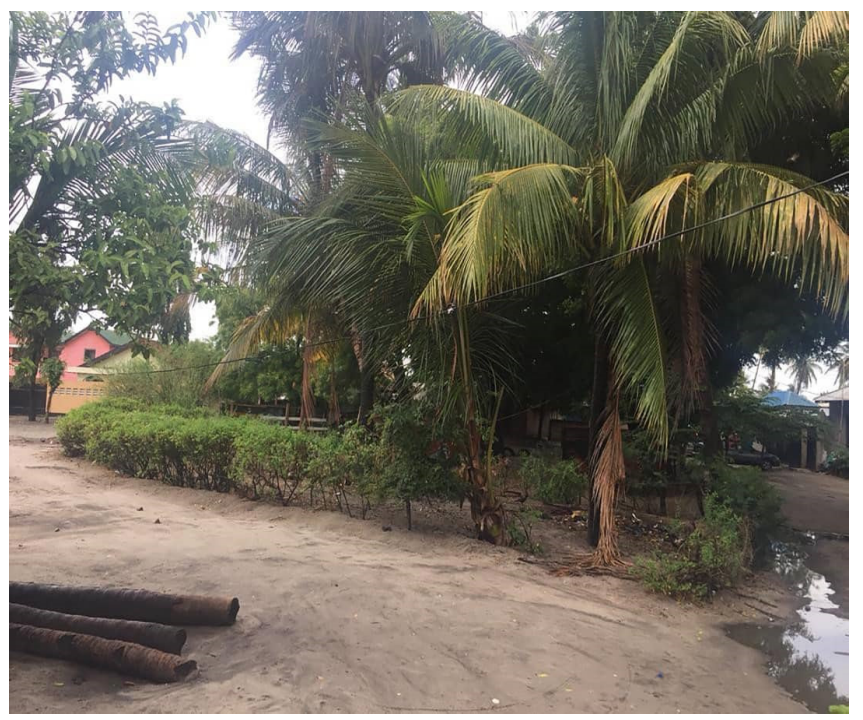

(c)

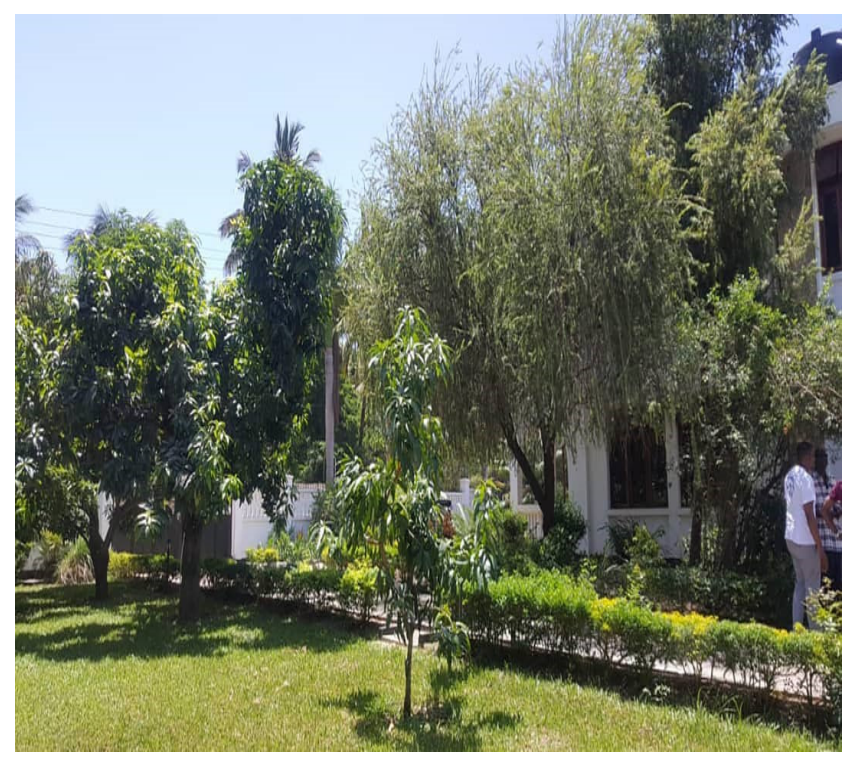

(b)

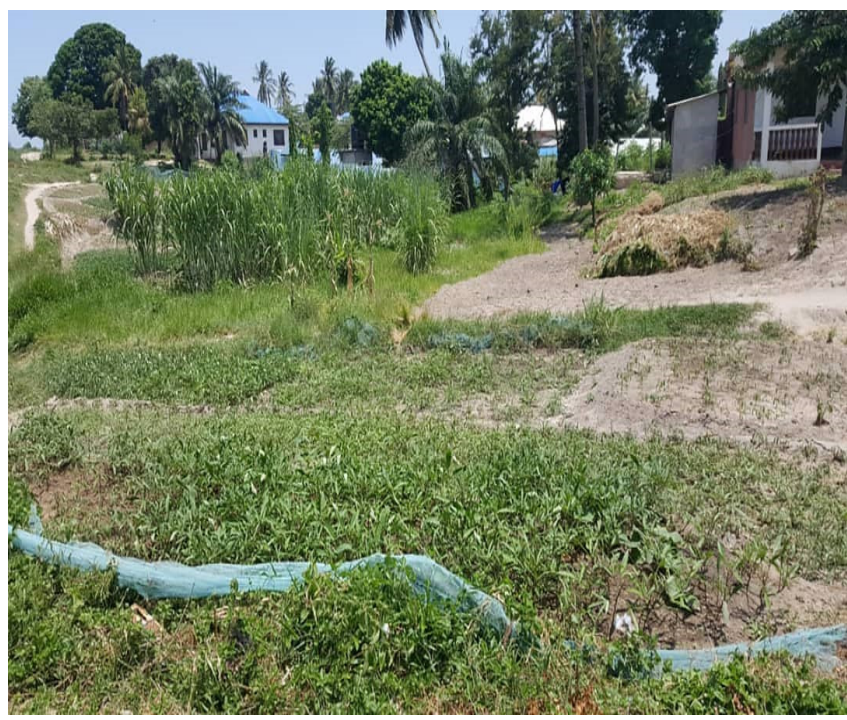

(d)

Plate 1. Combinations of green space types in Makumbusho (a), Kawe (b), Mburahati (c) and Yombo Vituka (d)

\subsubsection{Green Space Spatial Coverage}

Green space coverage in residential plots in case study areas was diverse since it ranged from $5 \mathrm{~m}^{2}$ to $1400 \mathrm{~m}^{2}$. Probably, this is due to differences in building densities, plot size, planning status, maturity of settlement and proximity to the City centre. To get an idea of the spatial coverage of greenery in the wards it was necessary to establish the average residential plot size. The results show that the average plot size area for each of the wards is inversely proportional to its building density. Table 2 shows the average coverage of green space in each ward which Makumbusho residential area had the smallest with an average of $263 \mathrm{~m}^{2}$, Mburahati $325 \mathrm{~m}^{2}$, Yombo Vituka $537 \mathrm{~m}^{2}$ and Kawe $1617 \mathrm{~m}^{2}$. Average greenery coverage per plot directly correlated to the plot size, of which Makumbusho had the lowest plot coverage at $13 \%$ while, Kawe had the highest at $31 \%$ of its plot area. The residential plots located in lowland areas or valleys had the highest green space coverage which the average green space per household was $116 \mathrm{~m}^{2} /$ plot followed by sloping land $\left(98 \mathrm{~m}^{2} / \mathrm{plot}\right)$. The least was households located in highland areas $\left(93 \mathrm{~m}^{2} / \mathrm{plot}\right)$. 
Table 2. Green space coverage in residential plots

\begin{tabular}{ccccccc}
\hline \multirow{2}{*}{$\begin{array}{c}\text { Settlement } \\
\text { Name }\end{array}$} & $\begin{array}{c}\text { Distance } \\
\text { from the city } \\
\text { centre (km) }\end{array}$ & $\begin{array}{c}\text { Building } \\
\text { density }\end{array}$ & Planning status & $\begin{array}{c}\text { Average plot } \\
\text { area per } \\
\text { household (sqm) }\end{array}$ & $\begin{array}{c}\text { Average Green } \\
\text { space coverage } \\
\text { per plot (sqm) }\end{array}$ & $\begin{array}{c}\text { Green space } \\
\text { coverage per } \\
\text { residential plot } \\
(\%)\end{array}$ \\
\hline Makumbusho & 5 & Very high & $54 \%$ unplanned & 263 & 34 & 13 \\
Mburahati & 6 & High & $71 \%$ unplanned & 323 & 82 & 25 \\
Yombo vituka & 10 & Medium & $60 \%$ unplanned & 537. & 86 & 16 \\
Kawe & 11.5 & Super low & $72 \%$ planned & $1,617$. & 505 & 31 \\
\hline
\end{tabular}

\subsubsection{Uses of Green Spaces}

The study revealed that green spaces are used for different social, economic and ecological functions. The most common uses include the provision of shade, recreation and aesthetic, biodiversity protection, food and dust control. Sixty-seven per cent $(67 \%)$ of the respondents from case studies use green spaces for more than one function and $33 \%$ for single use. The leading combination of multiple-uses of greenery is food and shade consisting of $10 \%$ followed by recreation, food and shade (5\%) and recreation, shade, food and biodiversity protection ( $2 \%)$. Other combinations consisted of less than $2 \%$.

In terms of single-use, $86 \%$ of the households indicated that they use green space for shade and cooling, $64 \%$ for food products, $25 \%$ for recreation and aesthetic, and $11 \%$ for dust control. Others included $8 \%$ for wind control, biodiversity protection (21\%), flood prevention (9\%), and stormwater control (1\%). The food products obtained from home greeneries were mainly used, for subsistence purposes rather than for sale. The sale of food products especially, from plot gardens, was done by low-income dwellers to supplement their earnings. According to the data, the settlements in which most of its households used green spaces for food provision were Mburahati and Yombo Vituka at 38\% each, followed by Makumbusho at 15\%. The use of plot greenery for shade was quite common in predominantly unplanned areas of Mburahati (35\%), Makumbusho (30\%), Yombo Vituka (22\%) and less used in the predominately planned Kawe areas (11\%). The diversity in greenery use might be caused by differences in building density, income levels, planning status of the ward and microclimate. The majority of Kawe residents are financially better off than their counterparts in unplanned settlements, and therefore, use other cooling means that include fans and air conditioners in their homes. While in low-income areas, the home greenery might be the only solution for cooling during day time.

\section{Discussion}

In the residential areas, greenery composed one-third of green spaces found within household plots and two thirds from areas not covered by plots. Dominant greenery in none plot areas was natural and semi-natural vegetation, while within residential areas, the plots were of woody plants, plots farms, vegetable and ornamental gardens. Overall, green spaces covered a third of the study area, of which $90 \%$ was occupied by natural and semi-natural vegetation. These findings are similar to other Cities in Africa like Addis Ababa, Ethiopia; Douala, Cameroon; Ouagadougou, Burkina Faso; and Saint Louis, Senegal (CLUVA, 2013). The dominance of vegetation is probably due to the City as located in the East African Region, previously covered by coastal forests. And therefore, none plot vegetation found in Dar es Salaam City is remnants of the former.

All three informal wards based on space standards used in planned areas had a greenery deficit, probably, due to high building density and lack of building codes. The deficit decreased with an increase in distance from the City centre. The planned Kawe ward had an excess of greenery, and possibly, due to the large institutional green spaces in the settlement. Despite the deficit of greenery in informal settlements, this study revealed that home greenery, especially trees acted as an alternative ameliorative method for alleviating environmental stresses such as high temperatures. Thus, there is a need to advocate capitalization on investing in green spaces. The spaces can provide services for the improvement of weather and climate regulation, storm water control, and therefore, indirectly contributing to climate change mitigation.

The distribution of greenery in the wards was inversely proportional to the building density, which decreased with an increase in distance from the City centre. Further, to some extent, by planning standards in the planned areas. Wards that had higher building density had less non-plot greenery coverage and vice versa. Consequently, the spatial coverage of non-plot greenery increased with distance from the City centre. The same was the case for the 
number of plots with farms, ornamental and vegetable gardens which increased with an increase of distance from the City centre. In contrast, the number of plots with woody plants (trees and shrubs) for shade in informal settlements increased with a decrease in distance from the City centre. This reflects the importance of having trees shade provision in high building density areas.

The majority of the households used greenery for shades, but more so, in informal wards near the City centre. Informal settlements located near the City centre, in comparison with, peri-urban areas have a large proportion of low-income households covered by high temperatures due to higher building density. Therefore, to be comfortable, especially during the daytime, shades of trees are used as cooling means because it is affordable. Greenery for food provision was more common in unplanned peripheral settlements due to the accessibility of ample space for some residents to engage in informal livelihood activity of food production. Ornamental gardens were more abundant in planned middle-income Kawe settlement because a big number of households could afford to develop and maintain gardens for the beautification of their residential plots. These findings show a strong relationship between the green spaces diversity and the quality of the urban environment, and the human being (Kopecká et al., 2017).

\section{Conclusion}

The study, based on interpretation of remotely sensed data and fieldwork has shown that green spaces in residential areas are composed of greenery found within and external to plot areas. Types of greenery found in none residential plot areas included natural and semi-natural vegetation, greenways; stream/rivers; playgrounds; open spaces; ruderal (abandoned green space); urban farms, wetlands; cemeteries/graveyards and seashore areas. Additionally, greenery within plots were woody plants, plot farms, vegetable and ornamental gardens.

Green spaces in none plot areas contributed in terms of spatial coverage, two-thirds of the residential greenery, with one third coming from within plots. Only a third of the study area was covered by greenery, out of which $90 \%$ was occupied by semi-natural vegetation. The residential areas closer to the City centre comparing with those afar were less greenery, probably due to their higher building densities. The majority, slightly above three-quarters of plots, had one or more greenery types, and the remaining did not have any green spaces. In terms of woody vegetation distribution, the number of residential plots with woody plants for shade was higher in the wards closer to the City. Meanwhile, the number of plot farms and vegetable gardens increased with an increase in distance from the City centre. It is worth noting that, Kawe as a planned area and yet furthest from the City centre, had higher amounts of natural and semi-natural vegetation, vegetable and ornamental gardens. Probably, this is due to its planned status and residents with higher incomes to develop and maintain gardens. The main uses of greenery included shades, recreation and aesthetic, biodiversity protection, food and dust control. Shade was the most common use but the households near the City had higher usage than those living afar. The plots with farms were more abundant in peripheral wards of the City except for the planned ward of Kawe.

\section{Acknowledgements}

We like to express our heartfelt thanks to all the people who contributed in different ways to make this publication possible. Firstly, we thank the Almighty God for his grace, protection and ability he gave us to do and complete this publication. Secondly, we are honoured to extend our sincere gratitude to Prof. Gabriel Kassenga, and Dr. Patrick O'Farrell for their involvement during manuscript preparation. Last but least, we thank DAAD and Ardhi University for financial support.

\section{References}

Bolund, P., \& Hunhammar, S. (1999). Ecosystem services in urban areas. Ecological economics, 29(2), 293-301. https://doi.org/10.1016/S0921-8009(99)00013-0

Campbell, K. (2001). Rethinking open space, open space provision and management: a way forward.

Clothier, B. E., Green, S. R., Müller, K., Gentile, R., Herath, I. K., Mason, K. M., \& Holmes, A. (2013). Orchard ecosystem services: bounty from the fruit bowl. Ecosystem services in New Zealand: conditions and trends, 94-101.

CLUVA. (2013). Deliverable 2.10 "Evaluation of the potential of urban ecosystem services" Final deliverable of Task 2.2 of the European Union CLUVA project (ENV.2010.2.1.5-1).

Costanza, R., d'Arge, R., De Groot, R., Farber, S., Grasso, M., Hannon, B., ... Paruelo, J. (1997). The value of the world's ecosystem services and natural capital. nature, 387(6630), 253. https://doi.org/10.1038/387253a0

Chen, Y. (2018). How green are residential areas? An analysis of community greening emerging multi-source geodata. BioRxiv, 434381. https://doi.org/10.1101/434381 
Delshammar, T., Östberg, J., \& Öxell, C. (2015). Urban Trees and Ecosystem Disservices--A Pilot Study Using Complaints Records from Three Swedish Cities. Arboriculture \& Urban Forestry, 41(4).

Esbah, H., Cook, E. A., \& Ewan, J. (2009). Effects of increasing urbanization on the ecological integrity of open space preserves. Environmental management, 43(5), 846-862. https://doi.org/10.1007/s00267-009-9274-z

Georgi, J. N., \& Dimitriou, D. (2010). The contribution of urban green spaces to the improvement of environment in cities: Case study of Chania, Greece. Building and Environment, 45(6), 1401-1414. https://doi.org/10.1016/j.buildenv.2009.12.003

Giergiczny, M., \& Kronenberg, J. (2014). From valuation to governance: using choice experiment to value street trees. Ambio, 43(4), 492-501. https://doi.org/10.1007/s13280-014-0516-9

Hassan, A. (2015). Assessment of community's participation in conservation of open spaces in Dar es salaam city, Tanzania. Sokoine University of Agriculture.

Jim, C., \& Chen, W. Y. (2006). Recreation-amenity use and contingent valuation of urban greenspaces in Guangzhou, China. Landscape and Urban Planning, 75(1-2), 81-96. https://doi.org/10.1016/j.landurbplan.2004.08.008

Karaca, S., Gülser, F., \& Selçuk, R. (2018). Relationships between soil properties, topography and land use in the Van Lake Basin, Turkey. Eurasian Journal of Soil Science, 7(2), 115-120.

Kibassa, D., \& Shemdoe, R. (2016). Land Cover Change in Urban Morphological Types of Dar es Salaam and Its Implication for Green Structures and Ecosystem Services. https://doi.org/10.15341/mese(23332581)/03.02.2016/005

Kiunsi, R. (2016). Dar es Salaam, Tanzania. In Barlett, S., \& Satterthwaite (Eds.), Cities on a

finite planet: Towards transformative responses to climate change. Routledge New York.

Kopecká, M., Szatmári, D., \& Rosina, K. (2017). Analysis of urban green spaces based on sentinel-2A: case studies from Slovakia. Land, 6(2), 25. https://doi.org/10.3390/land6020025

La Greca, P., La Rosa, D., Martinico, F., \& Privitera, R. (2011). Agricultural and green infrastructures: The role of non-urbanised areas for eco-sustainable planning in a metropolitan region. Environmental Pollution, 159(8), 2193-2202. https://doi.org/10.1016/j.envpol.2010.11.017

Lupala, J., \& Kiunsi, R. (2011). Dar es Salaam city, 50 years to come: conceptual considerations. In Unpublished working workshop paper presented during the (Vol. 50).

McPherson, E. G., \& Muchnick, J. (2005). Effects of street tree shade on asphalt concrete pavement performance.

Mensah, C. A. (2014). Urban green spaces in Africa: nature and challenges. International Journal of Ecosystem, $4(1), 1-11$.

Mng'ong'o, O. S. (2005). A Browning process: the case of Dar es Salaam city. KTH.

Mwageni, N. (2019). Development and application of an approach and model for determining the economic value of green spaces in Dar es Salaam City, Tanzania. Ardhi University.

Roy, M., Shemdoe, R., Hulme, D., Mwageni, N., \& Gough, A. (2018). Climate change and declining levels of green structures: Life in informal settlements of Dar es Salaam, Tanzania, Landscape and Urban Planning. https://doi.org/10.1016/j.landurbplan.2017.11.011

Tan, Z., Lau, K. K.-L., \& Ng, E. (2016). Urban tree design approaches for mitigating daytime urban heat island effects in a high-density urban environment. Energy and Buildings, 114, 265-274. https://doi.org/10.1016/j.enbuild.2015.06.031

Taylor, J. R., Lovell, S. T., Wortman, S. E., \& Chan, M. (2017). Ecosystem services and tradeoffs in the home food gardens of African American, Chinese-origin and Mexican-origin households in Chicago, IL. Renewable Agriculture and Food Systems, 32(1), 69-86. https://doi.org/10.1017/S174217051600003X

Thani, S. K. S. O., Hashim, N. H. M., Mohamad, N. H. N., Syed, S. A. M. A. J., \& Rahman, A. (2018). Vegetation Design as User's Thermal Modifier at Urban Park. Environment-Behaviour Proceedings Journal, 3(7), 227 234. https://doi.org/10.21834/e-bpj.v3i7.1243

Wang, Y., Bakker, F., De Groot, R., \& Wörtche, H. (2014). Effect of ecosystem services provided by urban green infrastructure on indoor environment: A literature review. Building and Environment, 77, 88-100. https://doi.org/10.1016/j.buildenv.2014.03.021 


\section{Copyrights}

Copyright for this article is retained by the author(s), with first publication rights granted to the journal.

This is an open-access article distributed under the terms and conditions of the Creative Commons Attribution license (http://creativecommons.org/licenses/by/4.0/). 